\title{
BMJ Open Access to healthcare for men and women with disabilities in the UK: secondary analysis of cross- sectional data
}

\author{
Dikaios Sakellariou, ${ }^{1}$ Elena S Rotarou ${ }^{2}$
}

To cite: Sakellariou D, Rotarou ES. Access to healthcare for men and women with disabilities in the UK: secondary analysis of crosssectional data. BMJ Open 2017;7:e016614. doi:10.1136/ bmjopen-2017-016614

- Prepublication history and additional material are available. To view, please visit the journal online (http://dx.doi.org/10. 1136/bmjopen-2017-016614).

Received 27 February 2017 Revised 22 May 2017 Accepted 20 June 2017

CrossMark

${ }^{1}$ School of Healthcare Sciences, Cardiff University, Cardiff, UK ${ }^{2}$ Department of Economics, University of Chile, Santiago, Chile

Correspondence to Dr Dikaios Sakellariou; sakellarioud@cardiff.ac.uk

\section{ABSTRACT}

Objectives The aim of this study was to investigate differences in access to healthcare between people with and without disabilities in the UK. The hypotheses were that: (1) people with disabilities would be more likely to have unmet healthcare needs and (2) there would be gender differences, with women more likely to report unmet needs.

Setting and participants We performed secondary analysis, using logistic regressions, of deidentified crosssectional data from the European Health Interview Survey, Wave 2. The sample included 12840 community-dwelling people over the age of 16 from across the UK, 5236 of whom had a disability. The survey method involved faceto-face and telephone interviews.

Outcome measures Unmet need for healthcare due to long waiting lists or distance or transportation problems; not being able to afford medical examination, treatment, mental healthcare or prescribed medicines. All measures were self-reported.

Results Adjusting for age, sex and other factors, people with a severe disability had higher odds of facing unmet needs. The largest gap was in 'unmet need for mental healthcare due to cost', where people with a severe disability were 4.5 times ( $\mathrm{Cl} 95 \% 2.2$ to 9.2) more likely to face a problem, as well as in 'unmet need due to cost of prescribed medicine', where people with a mild disability had 3.6 (CI 95\% 2.2 to 5.9) higher odds of facing a difficulty. Women with a disability were 7.2 times $(\mathrm{Cl}$ $95 \% 2.7$ to 19.4) more likely to have unmet needs due to cost of care or medication, compared with men with no disability.

Conclusions People with disabilities reported worse access to healthcare, with transportation, cost and long waiting lists being the main barriers. These findings are worrying as they illustrate that a section of the population, who may have higher healthcare needs, faces increased barriers in accessing services.

\section{INTRODUCTION}

Disability is common in the population in the UK. According to the Equality Act 2010, ${ }^{1}$ a person is disabled if they have a physical or mental impairment that has a substantial and long-term negative effect on their daily life. This definition moves beyond biomedical
Strengths and limitations of this study

- This study is based on a nationally-representative sample of community-dwelling men and women.

- We used a variety of outcome measures to capture the reasons that impact access to healthcare for people with disabilities.

- All outcome measures were self-reported, which may have introduced response bias.

- The study's cross-sectional design precludes any causal inference.

definitions that equate impairment with disability and addresses the social dimension of disability. It is estimated that $19 \%$ of the population live with a disability. ${ }^{2}$ Despite this, disabled people's access to healthcare services in the UK has been little explored. Access to healthcare has several dimensions: service availability, use of services, and relevance of services. ${ }^{3}$ In this article, we focus on the use of services and barriers to it, with a specific emphasis on unmet healthcare needs.

The British National Health Service (NHS) has been built on the principle of delivering equal access to healthcare for all. As Wenzl et at stress, the NHS should be expected to work towards greater access to healthcare and a reduction in health inequalities. However, the extent that this has either been realised or operationalised through the establishment of concrete policies is debatable. ${ }^{5}$ Powell and Exworthy ${ }^{6}$ argue that most of the NHS policies that aim to provide an equitable service focus on service availability rather than on any other dimension of access and conclude that there is a "...discrepancy between the 'paper' aim of equal access and the operational aim of equal provision" (p.59). The 2010 Equity and Excellence document ${ }^{7}$ put service accessibility at its core, but failed to either acknowledge people's 
differential demands to healthcare or the different resources that people have at their disposal.

In the UK, there are well-evidenced, long-standing inequalities both in terms of access to healthcare, unmet need, and health outcomes. ${ }^{8-11}$ However, there is only limited information about access to healthcare for people with disabilities. The available information shows that people with disabilities report worse access (including physical access into buildings) to services and worse satisfaction with provided services, that their needs are not recognised, and that they generally face several barriers, both structural (eg, lack of transportation), financial, and cultural (eg, misconceptions about disability). ${ }^{12-14}$ Various studies have shown that disability is an added impediment in accessing health services. ${ }^{15-19}$ A systematic review $^{13}$ on access to healthcare demonstrated that "... disabled people are restricted in accessing healthcare and report less satisfaction with their medical care" (p.21). Some of the barriers to healthcare access include lack of transport and inaccessible buildings. ${ }^{13}$ People with disabilities often report that their needs are not understood or that they are treated as patients of low priority. ${ }^{13}$ There is also a gender dimension, with women with disabilities often facing additional barriers in accessing healthcare services. ${ }^{20}$

The aim of this study is to explore access to healthcare for people with disabilities in the UK, and more specifically, to uncover possible differences in unmet healthcare needs between people with and without disabilities. Another aim of the study is to examine if there are gender differences in access to healthcare for people with disabilities. This study seeks to contribute to existing knowledge regarding access to healthcare for disabled people in the UK, by producing population-level evidence and exploring the role of factors-such as cost and long waiting lists-as significant determinants behind barriers to such services. This knowledge can guide policy-makers in the design of comprehensive support systems to enable real access to services, addressing not only the availability of services but also their use.

The study's hypotheses are that: (1) people with disabilities are more likely to have unmet healthcare needs and (2) there are gender differences in unmet healthcare needs, with women more likely to report more unmet needs than men.

In this article, we use the term people with disabilities to refer to people who have a long-standing (more than 6 months) health condition or impairment and experience activity limitations, as per the available data from the European Health Interview Survey (EHIS, Wave 2).

\section{METHODOLOGY}

\section{Methods}

We performed secondary analysis, using logistic regressions, of deidentified cross-sectional data from EHIS, Wave 2. The UK opted out from the first EHIS wave (2006-2009), but did take part in the 2014 EHIS, Wave
2. Data for England, Wales, and Scotland were collected between April 2013 and March 2014, and for Northern Ireland between April and September 2014. The survey was carried out as a follow-up to the Labour Force Survey (LFS). In England, Wales, and Scotland individuals who did not object in their final wave of contact, in the sampled households, completed the EHIS Wave 2 questionnaire. In Northern Ireland, a simple random sample of households on the Land and Property Services Agency property gazetteer, listing private households in Northern Ireland, was used. ${ }^{21}$ Access to the dataset was granted by the UK Data Service (www.ukdataservice.ac.uk).

The sample design stratified households by (1) country (England, Wales, Scotland, and Northern Ireland), (2) mode (face-to-face interviews, accounting for $20 \%$ of all interviews, and telephone interviews), and (3) final wave of LFS contact. $^{21}$ The UK survey targeted individuals over the age of $16^{21}$ and included a total of 20161 observations, a sample size which was much higher than the estimated minimum effective size for the country, which was $13085 .{ }^{22}$ The microdata did not include any information, such as names or addresses, that would allow direct identification. To ensure a high level of confidentiality, a set of anonymisation rules was applied. ${ }^{23}$

The EHIS consists of four modules: (1) socioeconomic and demographic variables, such as age, sex, marital status and so on; (1) variables on health status, for example self-assessed health, chronic conditions, limitations in daily activities and so on; (3) variables on healthcare use, such as consultations, unmet needs, preventive actions and so on and (4) health determinants, for instance weight, smoking, alcohol consumption and so on. ${ }^{24}$ The questions analyse 21 areas of health concerns/related behaviours and 81 specific item questions. ${ }^{25}$ All of the measures are self-reported, relying on the answers given by participants.

\section{Data and variables}

To define the variable 'disability', the answers to two questions were merged into a new variable. The first question (HS2) was 'Long-standing health problem: Suffer from any illness or health problem of a duration of at least 6 months', with answers yes/no. The second one (HS3) was 'General activity limitation: Limitation in activities people usually do because of health problems for at least the past 6 months', with the possible answers being 'severely limited', 'limited but no severely' and 'not limited at all'. Thus, the variable 'disability' included three possible answers: 'no disability' (that is, no longstanding health problem), 'mild disability' (people who answered 'yes' to HS2 and 'limited but not severely' to HS3), and 'severe disability' (people who answered 'yes' to HS2 and 'severely limited' to HS3). According to this categorisation, the total number of observations for 'disability' was 15493. Due to case deletion (default in STATA), the sample size varies between 11278 and 12840 observations; since we wanted to maximise sample size/ power, we allowed for slight fluctuations in sample sizes. 
Case deletion-which analyses cases with available data on each variable-did reduce statistical power; however, since we still have a large sample, statistical power is considered sufficiently high. The sample is representative of the target population, in terms of disability and age (for testing and descriptive statistics between full sample and study's sample, please see online supplementary materials 1 and 2).

Regarding introducing bias, we agree with Allison, ${ }^{26}$ who stated that "if listwise deletion still leaves you with a large sample, you might reasonably prefer it over maximum likelihood or multiple imputation [...] The other methods either get the standard errors wrong, the parameter estimates wrong, or both. At a minimum, listwise deletion gives you 'honest' standard errors that reflect the actual amount of information used (no page)".

We used the following five binary variables to assess unmet healthcare needs: (1) unmet need for healthcare in the past 12 months due to long waiting list(s); (2) unmet need for healthcare in the past 12 months due to distance or transportation problems; (3) could not afford medical examination or treatment in the past 12 months; (4) could not afford prescribed medicines in the past 12 months; and (5) could not afford mental healthcare (by a psychologist or a psychiatrist, for example) in the past 12 months. All of these were self-reported measures.

The control variables included the following: (1) gender: male/female; (2) age: 16-29/30-44/45-59/6079/80+; (3) civil status: unmarried/married/widowed/ divorced; (4) region: England, Wales, Scotland, Northern Ireland; (5) urbanisation level: densely populated area/intermediate-populated area/thinly populated area; (6) nationality: British/not British; (7) employment: employed/unemployed/inactive; (8) education: secondary/tertiary, technical/tertiary, university; (9) health self-assessment: good/fair/bad; and (10) income quintiles (net monthly equivalised household income): below first quintile/between first and second quintile/ between second and third quintile/between third and fourth quintile/between fourth and fifth quintile (for more information on the variables, please see http://ec. europa.eu/eurostat/web/products-manuals-and-guidelines/-/KS-RA-13-018). We performed logistic regressions using STATA SE V.11.2 to investigate a) unmet healthcare needs between people with and without disabilities; and b) unmet healthcare needs between men and women.

\section{RESULTS}

\section{Descriptive statistics}

Table 1 summarises the characteristics of the study sample.

Figure 1 shows the frequency distribution of unmet healthcare needs in the UK between people without a disability, people with a mild disability and people with a severe disability.

As can be seen in figure 1, the highest percentage of people with unmet healthcare needs are people with a severe disability. The highest percentage of people having an unmet need is the one related to long waiting list, and the smallest one is the one associated with unmet need for mental healthcare due to cost. All differences are statistically significant.

\section{Logistic regressions}

Logistic regressions were employed to investigate the impact of various factors on unmet needs for healthcare in the UK. The first logistic regressions (table 2) looked into unmet healthcare needs between people without a disability, people with a mild disability, and people with a severe disability. The results in table 2 include first sex and age-adjusted ORs and then fully-adjusted ORs (adjusted for all variables available in table 1). No collinearity distorted the results. There was a relatively higher correlation between the five groups of age (with a variance inflation factor (VIF) between 2.33 and 5.30). However, this is often the case when dealing with dummy variables that represent a categorical variable with three or more categories and-being relatively small-they have no effect on the regression. ${ }^{27}$ The mean VIF for all variables was 1.86 .

The results of the logistic regressions are shown in table 2.

As it can be seen from table 2, people with a severe disability are the most likely to face unmet needs, followed by people with a mild disability. The largest gap can be seen in the category of 'unmet need for mental healthcare due to cost', where people with a disability were from 4.5 to 7.2 times more likely to face a problem, as well as in the category 'unmet need due to cost of prescribed medicine', where they were from 3.6 to 5.4 times more likely to face a difficulty. Transportation was also an important barrier, with people with a disability being between 2 and 4.3 times more likely to face an unmet need because of this. The smallest gap was in 'unmet need due to long waiting list(s)', where people with disabilities were 2 to 2.4 times more likely to face a problem than people without a disability.

The logistic regressions in table 3 show gender differences in unmet healthcare needs. The two subcategories of disability (mild and severe) were joined into one, 'people with disabilities'. Thus, we have four categories: men without disabilities, women without disabilities, men with disabilities, and women with disabilities.

As seen in table 3, people without a disability—both men and women-were less likely to have unmet healthcare needs than people with a disability, with disabled women consistently facing more barriers than disabled men. Women with a disability were 7.2 times more likely to have unmet mental healthcare needs due to cost and 5.2 times more likely to have unmet needs due to cost of prescribed medicines, compared with men with no disability. Also, men with disabilities were more likely to face difficulties than men without disabilities: for example, disabled men were 3.9 times more likely to have an unmet healthcare need due to the cost of prescribed medicines. The pattern than we can observe in table 3 is 
Table 1 Comparison among people without a disability, people with a mild disability, and people with a severe disability

\begin{tabular}{|c|c|c|c|c|c|c|c|}
\hline \multirow[b]{2}{*}{ Parameter } & \multicolumn{2}{|c|}{$\begin{array}{l}\text { Without a disability } \\
(\mathrm{n}=7550)\end{array}$} & \multicolumn{2}{|c|}{$\begin{array}{l}\text { With a mild disability } \\
(n=3761)\end{array}$} & \multicolumn{2}{|c|}{$\begin{array}{l}\text { With a severe disability } \\
(n=1469)\end{array}$} & \multirow{2}{*}{$\begin{array}{l}\text { p Value, } \\
\chi^{2} \text { test }^{*}\end{array}$} \\
\hline & $\mathbf{n}$ & $\%$ & $\mathbf{n}$ & $\%$ & $n$ & $\%$ & \\
\hline \multicolumn{8}{|l|}{ Gender } \\
\hline Male $(n=5573)$ & 3345 & 44.3 & 1595 & 42.4 & 633 & 43.1 & \multirow[t]{2}{*}{$p=0.182$} \\
\hline Female $(n=7207)$ & 4205 & 55.7 & 2166 & 57.6 & 836 & 56.9 & \\
\hline \multicolumn{8}{|l|}{ Age groups } \\
\hline $16-29(n=1077)$ & 898 & 11.9 & 147 & 3.9 & 32 & 2.2 & \multirow[t]{5}{*}{$p<0.0001$} \\
\hline $30-44(n=2685)$ & 2114 & 28.0 & 440 & 11.7 & 131 & 8.9 & \\
\hline $45-59(n=3387)$ & 2159 & 28.6 & 850 & 22.6 & 378 & 25.7 & \\
\hline $60-79(n=4827)$ & 2144 & 28.4 & 1956 & 52.0 & 727 & 49.5 & \\
\hline $80+(n=806)$ & 234 & 3.1 & 369 & 9.8 & 203 & 13.8 & \\
\hline \multicolumn{8}{|l|}{ Urbanisation (degree) } \\
\hline $\begin{array}{l}\text { Densely populated area } \\
(\mathrm{n}=7570)\end{array}$ & 4447 & 58.9 & 2253 & 59.9 & 870 & 59.2 & \multirow[t]{3}{*}{$p=0.978$} \\
\hline $\begin{array}{l}\text { Intermediate-populated area } \\
(\mathrm{n}=3416)\end{array}$ & 2039 & 27.0 & 989 & 26.3 & 388 & 26.4 & \\
\hline $\begin{array}{l}\text { Thinly populated area } \\
(\mathrm{n}=1796)\end{array}$ & 1065 & 14.1 & 519 & 13.8 & 212 & 14.4 & \\
\hline \multicolumn{8}{|l|}{ Regions } \\
\hline England $(\mathrm{n}=10549)$ & 6244 & 82.7 & 3133 & 83.3 & 1172 & 79.8 & \multirow[t]{4}{*}{$p=0.002$} \\
\hline Wales $(n=592)$ & 317 & 4.2 & 184 & 4.9 & 91 & 6.2 & \\
\hline Scotland $(n=1103)$ & 672 & 8.9 & 316 & 8.4 & 115 & 7.8 & \\
\hline Northern Ireland $(n=536)$ & 317 & 4.2 & 128 & 3.4 & 91 & 6.2 & \\
\hline \multicolumn{8}{|l|}{ Civil status } \\
\hline Not married $(\mathrm{n}=2389)$ & 1706 & 22.6 & 496 & 13.2 & 187 & 12.7 & \multirow[t]{4}{*}{$\mathrm{p}<0.0001$} \\
\hline Married $(n=6995)$ & 4394 & 58.2 & 1944 & 51.7 & 657 & 44.7 & \\
\hline Widowed $(n=1747)$ & 642 & 8.5 & 748 & 19.9 & 357 & 24.3 & \\
\hline Divorced $(n=1649)$ & 808 & 10.7 & 572 & 15.2 & 269 & 18.3 & \\
\hline \multicolumn{8}{|l|}{ Nationality } \\
\hline British $(n=12279)$ & 7157 & 94.8 & 3682 & 97.9 & 1440 & 98.0 & \multirow[t]{2}{*}{$p<0.0001$} \\
\hline Not British $(n=501)$ & 393 & 5.2 & 79 & 2.1 & 29 & 2.0 & \\
\hline \multicolumn{8}{|l|}{ Employment } \\
\hline Employed ( $n=5752)$ & 4507 & 59.7 & 1091 & 29.0 & 154 & 10.5 & \multirow[t]{3}{*}{$\mathrm{p}<0.0001$} \\
\hline Unemployed $(\mathrm{n}=551)$ & 310 & 4.1 & 188 & 5.0 & 53 & 3.6 & \\
\hline Inactive $(n=6477)$ & 2733 & 36.2 & 2482 & 66.0 & 1262 & 85.9 & \\
\hline \multicolumn{8}{|l|}{ Education } \\
\hline Secondary $(n=8558)$ & 4606 & 61.0 & 2764 & 73.5 & 1188 & 80.9 & \multirow[t]{3}{*}{$p<0.0001$} \\
\hline Tertiary, technical $(n=1954)$ & 1231 & 16.3 & 553 & 14.7 & 170 & 11.6 & \\
\hline Tertiary, university $(\mathrm{n}=2268)$ & 1714 & 22.7 & 444 & 11.8 & 110 & 7.5 & \\
\hline \multicolumn{8}{|l|}{ Health self-assessment } \\
\hline $\operatorname{Bad}(n=1389)$ & 23 & 0.3 & 530 & 14.1 & 836 & 56.9 & \multirow[t]{3}{*}{$\mathrm{p}<0.0001$} \\
\hline Fair $(n=2626)$ & 408 & 5.4 & 1771 & 47.1 & 447 & 30.4 & \\
\hline Good $(n=8766)$ & 7120 & 94.3 & 1459 & 38.8 & 187 & 12.7 & \\
\hline Income quintiles & & & & & & & \\
\hline
\end{tabular}


Table 1 Continued

\begin{tabular}{|c|c|c|c|c|c|c|c|}
\hline \multirow[b]{2}{*}{ Parameter } & \multicolumn{2}{|c|}{$\begin{array}{l}\text { Without a disability } \\
(\mathrm{n}=7550)\end{array}$} & \multicolumn{2}{|c|}{$\begin{array}{l}\text { With a mild disability } \\
(n=3761)\end{array}$} & \multicolumn{2}{|c|}{$\begin{array}{l}\text { With a severe disability } \\
(n=1469)\end{array}$} & \multirow{2}{*}{$\begin{array}{l}\text { p Value, } \\
\chi^{2} \text { test }^{\star}\end{array}$} \\
\hline & $\mathbf{n}$ & $\%$ & $\mathbf{n}$ & $\%$ & $\mathbf{n}$ & $\%$ & \\
\hline $\begin{array}{l}\text { Between first and second } \\
\text { quintile }(n=2760)\end{array}$ & 1480 & 19.6 & 880 & 23.4 & 400 & 27.2 & \\
\hline $\begin{array}{l}\text { Between third and fourth } \\
\text { quintile }(n=2431)\end{array}$ & 1699 & 22.5 & 545 & 14.5 & 187 & 12.7 & \\
\hline $\begin{array}{l}\text { Between fourth and fifth } \\
\text { quintile }(n=2265)\end{array}$ & 1638 & 21.7 & 523 & 13.9 & 104 & 7.1 & \\
\hline
\end{tabular}

*Sex and age adjusted.

that men without a disability are the least likely to have an unmet healthcare need, followed by women without a disability, then by men with a disability, and finally by women with a disability.

\section{DISCUSSION}

In this study, we investigated healthcare access for people with disabilities in the UK. Our hypotheses were that: (1) people with disabilities would be more likely to have unmet healthcare needs, and (2) women would be more likely to report unmet healthcare needs than men. The results supported both of these hypotheses: people with disabilities reported worse access to healthcare, with transportation, cost, and long waiting lists being the main barriers. Furthermore, women reported worse access to healthcare than men, across all categories. These findings are particularly worrying as they illustrate that a section of the population, who may have higher healthcare needs, face increased barriers in accessing much-needed services.

The strengths of the study are that it includes a nationally representative sample and that it focuses on several factors that affect access to healthcare, such as transportation and cost. One of the limitations of the study is that we cannot make any causal inferences as to the reasons for the observed inequalities in access to healthcare due to the cross-sectional nature of the data. Furthermore, the EHIS relies on self-reporting information, which leaves the instrument open to response bias; however, there is no relevant information on this aspect. This might have

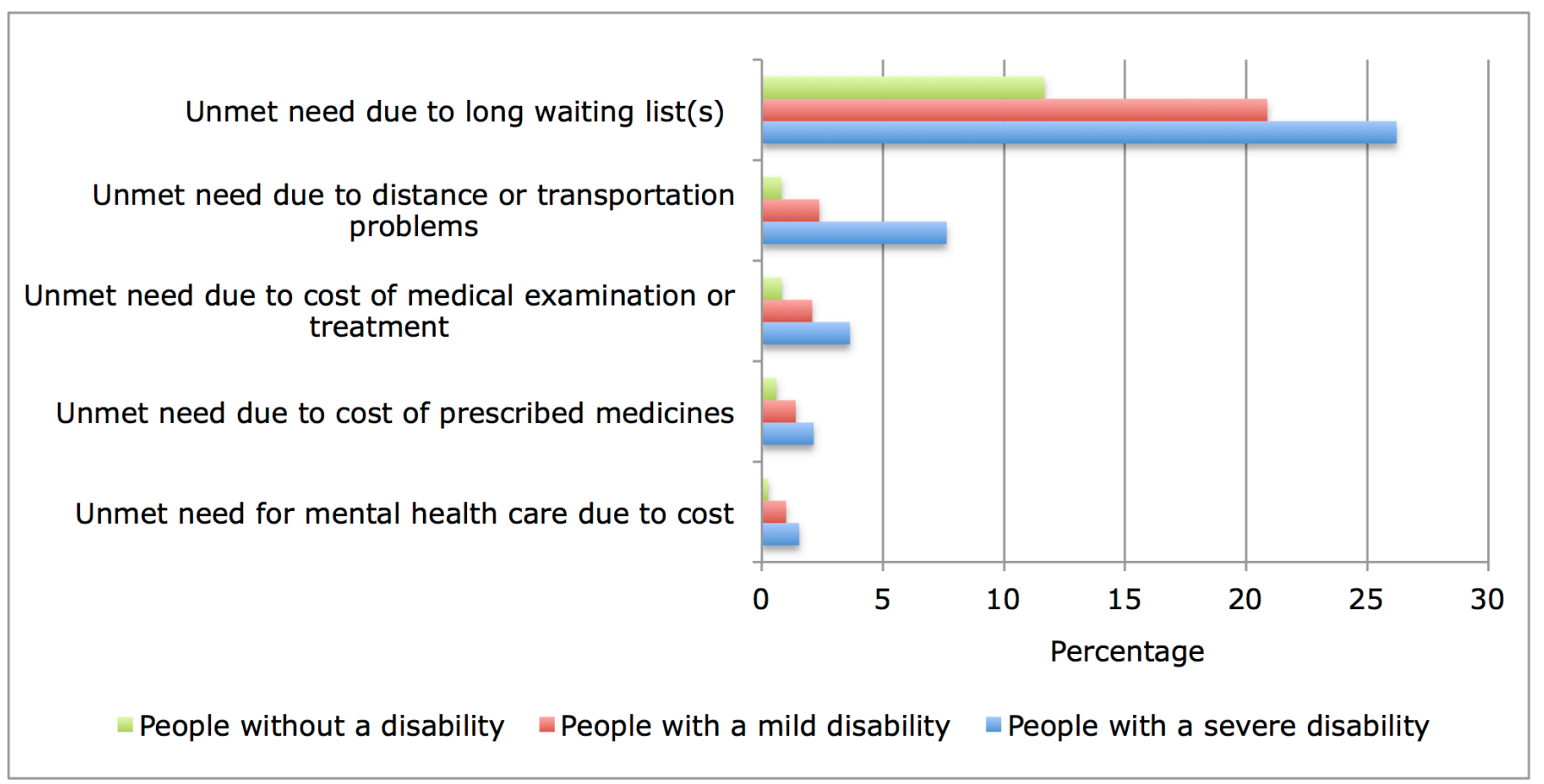

Figure 1 People with unmet healthcare needs (\%). 
Table 2 Unmet needs for healthcare between people without a disability, people with a mild disability, and people with a severe disability, adjusted ORs

\begin{tabular}{|c|c|c|}
\hline Parameters & $\begin{array}{l}\text { Sex and age-adjusted OR } \\
(95 \% \mathrm{Cl})\end{array}$ & $\begin{array}{l}\text { Fully-adjusted OR } \\
(95 \% \mathrm{Cl})\end{array}$ \\
\hline \multicolumn{3}{|c|}{ 1. Unmet need due to long waiting list(s) } \\
\hline People with a mild disability & $\begin{array}{l}2.37^{\star \star \star} \\
\text { (2.12 to } 2.65)\end{array}$ & $\begin{array}{l}1.98^{\star \star \star} \\
\text { (1.72 to } 2.27)\end{array}$ \\
\hline People with a severe disability & $\begin{array}{l}3.24^{\star \star \star} \\
\text { (2.81 to } 3.73 \text { ) }\end{array}$ & $\begin{array}{l}2.38^{\star \star \star} \\
\text { (1.96 to } 2.89)\end{array}$ \\
\hline \multicolumn{3}{|c|}{ 2. Unmet need due to distance or transportation problems } \\
\hline People with a mild disability & $\begin{array}{l}3.37^{\star \star \star} \\
(2.40 \text { to } 4.72)\end{array}$ & $\begin{array}{l}1.93^{\star \star} \\
\text { (1.26 to } 2.95)\end{array}$ \\
\hline People with a severe disability & $\begin{array}{l}11.37^{\star \star \star} \\
\text { (8.15 to } 15.87)\end{array}$ & $\begin{array}{l}4.32^{\star \star \star} \\
\text { (2.66 to } 7.00)\end{array}$ \\
\hline \multicolumn{3}{|c|}{ 3. Unmet need due to cost of medical examination or treatment } \\
\hline People with a mild disability & $\begin{array}{l}3.80^{\star \star \star} \\
(2.69 \text { to } 5.35)\end{array}$ & $\begin{array}{l}2.12^{\star \star} \\
(1.37 \text { to } 3.30)\end{array}$ \\
\hline People with a severe disability & $\begin{array}{l}6.54^{\star \star \star} \\
(4.46 \text { to } 9.60)\end{array}$ & $\begin{array}{l}3.35^{\star \star \star} \\
\text { (1.94 to } 5.80)\end{array}$ \\
\hline \multicolumn{3}{|c|}{ 4. Unmet need due to cost of prescribed medicines } \\
\hline People with a mild disability & $\begin{array}{l}4.15^{\star \star *} \\
\text { (2.76 to } 6.26)\end{array}$ & $\begin{array}{l}3.56^{\star \star \star} \\
(2.16 \text { to } 5.86)\end{array}$ \\
\hline People with a severe disability & $\begin{array}{l}6.51^{\star * \star} \\
(4.04 \text { to } 10.48)\end{array}$ & $\begin{array}{l}5.39^{\star \star \star} \\
(2.77 \text { to } 10.50)\end{array}$ \\
\hline \multicolumn{3}{|c|}{ 5. Unmet need for mental healthcare due to cost } \\
\hline People with a mild disability & $\begin{array}{l}4.15^{\star \star \star} \\
(2.76 \text { to } 6.26)\end{array}$ & $\begin{array}{l}4.45^{\star \star \star} \\
(2.15 \text { to } 9.18)\end{array}$ \\
\hline People with a severe disability & $\begin{array}{l}6.51^{\star \star \star} \\
(4.04 \text { to } 10.48)\end{array}$ & $\begin{array}{l}7.24^{\star \star \star} \\
(2.89 \text { to } 18.15)\end{array}$ \\
\hline
\end{tabular}

Reference: people without a disability.

Observations : (1) 12780; (2) 12840; (3) 12831; (4) 11677; (5) 11278.

${ }^{* *} p<0.01$. ${ }^{* * *} p<0.001$.

had an effect on the data, since studies have shown that there are gender differences to self-reported health, with women consistently reporting poorer health status than men. ${ }^{28}$ Also, disability was self-assessed, with limited questions, and it was not possible to disaggregate the results by impairment type. Finally, the EHIS did not collect any qualitative data in relation to the mechanisms that lead to compromised access to healthcare and how this is experienced by people with disabilities.

We found that people with a severe disability are the ones most likely to have an unmet healthcare need, being 7.2 times more likely to have an unmet mental healthcare need due to cost, than people without a disability. On the other hand, people with a mild disability were 3.6 times more likely to have an unmet need due to the cost of prescribed medicine, than people with no disability. These results agree with previous research. Popplewell $e a^{14}$ demonstrated how adults with physical disability in England report worse access to primary care, while Allerton and Emerson ${ }^{29}$ found similar inequalities in a UK national study with people with chronic conditions or impairments. Other research from the UK has shown that people with disabilities report worse experiences of cancer care. ${ }^{30}$

The available information from various countries suggests that people with disabilities are generally less likely to have good access to healthcare compared with people without. ${ }^{15-18}$ Access to preventive services is also affected. Several studies have evidenced how people with disabilities experience compromised access to cancer screening services. ${ }^{31-34}$

People with disabilities face structural, financial and cultural/attitudinal barriers when they seek to access healthcare. ${ }^{35}$ Difficulties in accessing healthcare can be caused by lack of transport, inaccessible buildings, and inadequate training of healthcare professionals, among other factors. ${ }^{1319}$ People with disabilities often report that they feel their needs are not understood, that they do not feel listened to and that they are perceived as patients of low priority due to their pre-existing condition. ${ }^{19}$ Such difficulties can be further compounded by the systematic exclusion that people with disabilities often face, exemplified by lower employment rates, lower income levels and higher levels of poverty than the general population. ${ }^{36}$ 
Table 3 Gender differences in unmet healthcare needs, adjusted ORs

\begin{tabular}{|c|c|c|c|c|}
\hline \multirow[b]{2}{*}{ Parameters } & \multicolumn{2}{|c|}{ Age-adjusted OR } & \multicolumn{2}{|c|}{ Fully-adjusted OR } \\
\hline & OR & $95 \% \mathrm{Cl}$ & OR & $95 \% \mathrm{Cl}$ \\
\hline \multicolumn{5}{|c|}{ 1. Unmet need due to long waiting list(s) } \\
\hline Men with a disability & $2.97^{\star \star \star}$ & 2.54 to 3.48 & $2.31^{\star \star \star}$ & 1.92 to 2.77 \\
\hline Women with a disability & $3.27^{\star \star \star}$ & 2.82 to 3.78 & $2.60^{\star \star *}$ & 2.18 to 3.09 \\
\hline Women without a disability & 0.83 & 0.51 to 1.37 & 0.74 & 0.44 to 1.23 \\
\hline Men with a disability & $4.30^{\star \star \star}$ & 2.77 to 6.66 & $1.70^{*}$ & 1.01 to 2.87 \\
\hline Women with a disability & $5.35^{\star \star \star}$ & 3.56 to 8.06 & $2.05^{\star \star}$ & 1.25 to 3.37 \\
\hline \multicolumn{5}{|c|}{$\begin{array}{l}\text { 3. Unmet need due to cost of medical } \\
\text { examination or treatment }\end{array}$} \\
\hline Women with a disability & $5.54^{\star \star \star}$ & 3.50 to 8.78 & $2.89^{\star \star \star}$ & 1.67 to 4.99 \\
\hline \multicolumn{5}{|c|}{$\begin{array}{l}\text { 4. Unmet need due to cost of prescribed } \\
\text { medicines }\end{array}$} \\
\hline Women without a disability & 1.47 & 0.79 to 2.74 & 1.42 & 0.76 to 2.65 \\
\hline Men with a disability & $5.22^{\star \star \star}$ & 2.76 to 9.87 & $3.92^{\star \star \star}$ & 1.92 to 8.01 \\
\hline Women with a disability & $6.70^{\star \star \star}$ & 3.75 to 11.95 & $5.20^{\star \star \star}$ & 2.68 to 10.09 \\
\hline \multicolumn{5}{|c|}{$\begin{array}{l}\text { 5. Unmet need for mental healthcare due } \\
\text { to cost }\end{array}$} \\
\hline Women without a disability & 1.49 & .56 to 3.97 & 1.55 & .58 to 4.16 \\
\hline
\end{tabular}

Reference: men without a disability.

Observations: (1) 12780; (2) 12840; (3) 12831; (4) 11677; (5) 11278.

${ }^{\star} \mathrm{p}<0.05,{ }^{* \star} \mathrm{p}<0.01 ;{ }^{* \star \star} \mathrm{p}<0.001$.

The findings are alarming for various reasons. People with disabilities often have greater healthcare needs and therefore may need to access healthcare services more than the general population. ${ }^{29}$ The existence of barriers in their access to healthcare may further compromise their health leading to a vicious cycle: poorer access to healthcare can lead to even poorer health. Barriers in accessing cancer-screening services can lead to lower use of such services compared with the general population, with subsequent delays in diagnosis. ${ }^{34}$

Furthermore, the results indicate that cost is a factor that affects use of healthcare, including prescription medication. While NHS Wales, NHS Scotland, and Health and Social Care in Northern Ireland have abolished prescription charges, NHS England, where the majority of the UK population reside and seek to access healthcare services, has not. Currently, NHS England offers exemptions from prescription charges to several categories of service users ${ }^{37}$ but most of the service users, including most people with disabilities, need to pay. This has led to a high proportion of people who do not collect prescription medications due to cost. ${ }^{38}$
The intersections between disability, socioeconomic condition, and gender affect access to healthcare. Previous studies show, for example, that access to healthcare is mediated by the type of health service provider, which is in turn mediated by income. ${ }^{39}$ As people with disabilities are often excluded from the job market and they also have higher daily living costs (for instance, increased heating costs if they spend more time at home, or out-of-pocket payments for equipment) ${ }^{40}$ they often cannot afford to pay for private coverage or out of pocket payments for medication. In their study, Beatty et $a l^{39}$ found that people "with the poorest health and with the lowest incomes were the least likely to receive all health services needed' ( 1417 ). Low income can affect access to healthcare in various ways through, for example, reduced access to suitable transportation and reduced ability to pay for medication or make out-of-pocket payments. This has a gender dimension too, with women consistently reporting worse access to healthcare. ${ }^{20}$

The results show that women with a disability were more likely to have an unmet healthcare need than any of the other groups (for example, they were 7.2 times more 
likely to have an unmet mental healthcare need due to cost if compared with men without a disability), followed by men with a disability (for instance, they were almost four times more likely to have an unmet healthcare need due to cost of prescribed medicines), and then by women without a disability (1.4 times more likely to have an unmet need due to long waiting lists compared with men with no disability). Our results agree with other international studies that have underlined gender differences in barriers to healthcare. ${ }^{41} 42$ One of the reasons for this may be the invisibility of the broader social dimensions of gender within healthcare systems, including the NHS. Healthcare systems often do not recognise the additional barriers that women may face when they seek healthcare; such barriers may, for example, be due to lower income or higher caring responsibilities compared with men. ${ }^{414}$

The fact that these results come from the UK, a country with a national, public and free at-the-point-of-access healthcare system (apart from prescriptions), is particularly worrying. The NHS aims to provide equal access to the population but this does not seem to be distributed equitably, especially when we consider use of services and not only their availability. The results show how the interaction of disability and gender can create a structural disadvantage for disabled women who report the worst access to healthcare from any other group.

To develop effective policies to move towards a more equitable healthcare access, it is important to explore in detail the reasons behind the worse access to healthcare services for people with disabilities, acknowledging the significance of gender in any exploration of access to services. It is important to acknowledge how multiple factors, such as disability, gender, and the social and financial realities these are embedded in, affect access to healthcare. It is imperative to determine the actual accessibility of healthcare rather than anticipated access based on the availability of services or the provision of health coverage, which do not always acknowledge people's specific needs (eg, transportation needs to reach a healthcare facility). Finally, it is equally important to understand that health inequalities are largely based on disparities in wider health determinants and therefore, policies aimed at achieving a more equitable distribution of health, need to address broader socioeconomic inequalities.

Acknowledgements We thank Hannah Kupper and Adam Wagner for the very useful comments they provided during the review process.

Contributors DS and ESR jointly conceived the final research question and aims and objectives, reviewed the literature, produced the analysis plan and carried out the analysis and drafted the manuscript.

Funding ESR's work was supported by the Conicyt-Fondecyt, Postdoctorate Programme under Project No. 3140481.

Competing interests None declared.

Provenance and peer review Not commissioned; externally peer reviewed.

Data sharing statement Technical appendix and dataset available from the UK Data Service. https://discover.ukdataservice.ac.uk/catalogue/?sn=7881

Open Access This is an Open Access article distributed in accordance with the Creative Commons Attribution Non Commercial (CC BY-NC 4.0) license, which permits others to distribute, remix, adapt, build upon this work non-commercially, and license their derivative works on different terms, provided the original work is properly cited and the use is non-commercial. See: http://creativecommons.org/ licenses/by-nc/4.0/

(c) Article author(s) (or their employer(s) unless otherwise stated in the text of the article) 2017. All rights reserved. No commercial use is permitted unless otherwise expressly granted.

\section{REFERENCES}

1. HM Government. Equality Act 2010. London: The Stationary Office, 2010.

2. Papworth Trust. Disability facts and figures. Cambridge: Papworth Trust, 2016. http://www.papworthtrust.org.uk/node/2206. (accessed 23 Feb 2017).

3. Gulliford M, Figueroa-Munoz J, Morgan M, et al. What does 'access to health care' mean? J Health Serv Res Policy 2002;7:186-8.

4. Wenzl M, McCuskee S, Mossialos E. Commissioning for equity in the NHS: rhetoric and practice. Br Med Bull 2015;115:5-17.

5. Morris S, Sutton M, Gravelle H. Inequity and inequality in the use of health care in England: an empirical investigation. Soc Sci Med 2005;60:1251-66.

6. Powell M, Exworthy M. Equal access to health care and the British National Health Service. Policy Studies 2003;24:51-64.

7. Department of Health. Equity and excellence: liberating the NHS. Norwich: The Stationary Office, 2010. https://www.gov.uk/ government/uploads/system/uploads/attachment_data/file/213823/ dh_117794.pdf. (accessed 23 Apr 2017).

8. Barr B, Bambra C, Whitehead M. The impact of NHS resource allocation policy on health inequalities in England 2001-11: longitudinal ecological study. BMJ 2014;348:g3231.

9. Ellis A, Fry, R. Regional health inequalities in England. Regional Trends 2010;42:60-79.

10. Goddard M, Smith P. Equity of access to health care services: theory and evidence from the UK. Soc Sci Med 2001;53:1149-62.

11. Marmot M, Society F. Healthy lives: the Marmot Review: strategic review of health inequalities in England post-2010. http://www. instituteofhealthequity.org/ (accessed 23 Apr 2017).

12. Emerson E, Madden R, Robertson J, et al. Intellectual and physical disability, social mobility, social inclusion \& health: Background paper for the Marmot review. Lancaster: Centre for Disability Research, Lancaster University, 2009. http://eprints.lancs.ac.uk/26403/1/ Disability_Social_Mobility_Social_Inclusion.pdf. (accessed 17 Feb 2017).

13. Gibson J, O'Connor R. Access to health care for disabled people: a systematic review. Social Care and Neurodisability 2010;1:21-31.

14. Popplewell NT, Rechel BP, Abel GA. How do adults with physical disability experience primary care? A nationwide cross-sectional survey of access among patients in England. BMJ Open 2014;4:e004714 http://bmjopen.bmj.com/content/4/8/e004714.

15. AlHW. Access to health services by Australians with disability 2012. AlHW bulletin no. 129. Cat. no. AUS 191. Canberra: AlHW 2015.

16. Lee JE, Kim HR, Shin HI. Accessibility of medical services for persons with disabilities: comparison with the general population in Korea. Disabil Rehabil 2014;36:1728-34.

17. Maart S, Jelsma J. Disability and access to health care - a community based descriptive study. Disabil Rehabil 2014;36:1489-93.

18. Rotarou ES, Sakellariou D. Inequalities in access to health care for people with disabilities in Chile: the limits of universal health coverage. Crit Public Health;20:1-13 http://www.tandfonline.com/ doi/full/.

19. Scheer J, Kroll T, Neri MT, et al. Access barriers for persons with disabilities: the consumer's perspective. J Disabil Policy Stud 2003;13:221-30.

20. Smith DL. Disparities in health care access for women with disabilities in the United States from the 2006 National Health Interview Survey. Disabil Health J 2008;1:79-88.

21. Office for National StatisticsNorthern Ireland Statistics and Research Agency. European Health Interview Survey: United Kingdom Data, Wave 2, 2013-2014: UK Data Service SN: 7881.2016 https:// discover.ukdataservice.ac.uk/catalogue/?sn=7881.

22. Eurostat. Description of the dataset: European Health Interview Survey (EHIS). http://ec.europa.eu/eurostat/web/microdata/ european-health-interview-survey (accessed $17 \mathrm{Aprl} 2017$ ).

23. Eurostat. Reference Metadata in Euro SDMX Metadata Structure: European Health Interview Survey (EHIS). 2016 http://ec. 
europa.eu/eurostat/cache/metadata/en/hlth_det_esms.htm\# conf1472805901915 (accessed 20 Apr 2017).

24. Office for National Statistics. Health indicators for the United Kingdom and its constituent countries based on the 2013 to 2014: European Health Interview Survey, (Wave 2). 2015 http://webarchive. nationalarchives.gov.uk/20160105160709/http://www.ons.gov.uk/ ons/rel/disability-and-health-measurement/health-indicators-basedon-the-european-health-interview-survey/2013-2014--wave-2-/ index.html (accessed 17 Apr 2017).

25. Eurostat. European Health Interview survey (EHIS wave 2). Methodological manual. Eurostat Methodologies and Working Papers. Luxembourg: Publications Office of the European Union, 2013.

26. Allison P. Listwise deletion: it's NOT evil. Statistical Horizons http:// statisticalhorizons.com/listwise-deletion-its-not-evil (accessed 30 Apr 2017).

27. Allison P. When can you safely ignore multicollinearity? Statistical Horizons $2012 \mathrm{http}: / /$ statisticalhorizons.com/multicollinearity (accessed 17 April 2017).

28. Boerma T, Verdese E, Hosseinpoor A, et al. Gender gap in selfreported health measures. Geneva: World Health Organisation, 2012. http://www.who.int/healthinfo/sage/SAGE_Meeting_Dec2012_ BoermaT.pdf. (accessed 22 Feb 2017).

29. Allerton L, Emerson E. British adults with chronic health conditions or impairments face significant barriers to accessing health services. Public Health 2012;126:920-7.

30. Bone A, McGrath-Lone L, Day S, et al. Inequalities in the care experiences of patients with cancer: analysis of data from the National Cancer Patient Experience Survey 2011-2012. BMJ Open 2014:4:e004567.

31. Angus J, Seto L, Barry N, et al. Access to cancer screening for women with mobility disabilities. J Cancer Educ 2012;27:75-82.
32. Peters K, Cotton A. Barriers to breast cancer screening in Australia: experiences of women with physical disabilities. J Clin Nurs 2015;24(3-4):563-72

33. Sakellariou D, Rotarou ES. Utilisation of cancer screening services by disabled women in Chile. PLoS One 2017;12:e0176270.

34. Merten JW, Pomeranz JL, King JL, et al. Barriers to cancer screening for people with disabilities: a literature review. Disabil Health $J$ 2015;8:9-16.

35. Drainoni $\mathrm{M}$, et al. Cross-disability experiences of barriers to health care access. J Disabil Policy Stu 2006;17:101-15.

36. Braithwaite J, Mont D. Disability and poverty: a survey of World Bank Poverty assessments and implications. ALTER - European Journal of Disability Research / Revue Europ?enne de Recherche sur le Handicap 2009;3:219-32.

37. NHS Choices. NHS in England - help with health costs. http://www. nhs.uk/NHSEngland/Healthcosts/Pages/Prescriptioncosts.aspx (accessed 24 Apr 2017).

38. Morri I. Prescriptions costs a barrier to healthcare. $2008 \mathrm{https} / /$ www.ipsos-mori.com/researchpublications/researcharchive/151/ Prescription-Costs-A-Barrier-To-Healthcare.aspx (accessed 23 Apr 2017).

39. Beatty P, Hagglund K, Neri M, et al. Access to health care services among people with chronic or disabling conditions: patterns and predictors. Arch Phys Med Rehab 2003;84:1417-25.

40. Zaidi A, Burchardt T. Comparing incomes when needs differ: equivalization for the extra costs of disability in the u.k. Rev Income Wealth 2005;51:89-114.

41. Gideon J. Engendering the Health Agenda? reflections on the chilean case, 2000-2010. Soc Polit 2012;19:333-60.

42. Gibson BE, Mykitiuk R. Health care access and support for disabled women in Canada: falling short of the UN Convention on the rights of persons with disabilities: a qualitative study. Womens Health Iss 2012;22:e111-8. 